Applied Psycholinguistics 24 (2003), 235-247

Printed in the United States of America

DOI: 10.1017.S0142716403000134

\title{
Nonword reading across orthographies: How flexible is the choice of reading units?
}

\author{
USHA GOSWAMI \\ University of Cambridge \\ JOHANNES C. ZIEGLER \\ CNRS and University of Provence
}

LOUISE DALTON

University of Cambridge

WOLFGANG SCHNEIDER

University of Würzburg

ADDRESS FOR CORRESPONDENCE

Usha Goswami, Faculty of Education, University of Cambridge, Shaftesbury Road, Cambridge CB2 2BX, UK.

\begin{abstract}
It was predicted that children learning to read inconsistent orthographies (e.g., English) should show considerable flexibility in making use of spelling-sound correspondences at different unit sizes whereas children learning to read consistent orthographies (e.g., German) should mainly employ small-size grapheme-phoneme strategies. This hypothesis was tested in a cross-language blocking experiment using nonwords that could only be read using small-size grapheme-phoneme correspondences (small-unit nonwords) and phonologically identical nonwords that could be decoded using larger correspondences (large-unit nonwords). These small-unit and large-unit nonwords were either presented mixed together in the same lists or blocked by unit size. It was found that English children, but not German children, showed blocking effects (better performance when items were blocked by nonword type than in mixed lists). This suggests that in mixed lists, English readers have to switch back and forth between small-unit and large-unit processing, resulting in switching costs. These results are interpreted in terms of differences concerning the grain size of the phonological recoding mechanisms developed by English and German children.
\end{abstract}

In the area of reading development, there has been considerable debate about the grain size of the orthography-phonology correspondences that are basic to the acquisition of reading. Some have argued that children initially use small-

(C) 2003 Cambridge University Press $0142-7164 / 03 \$ 12.00$ 
size correspondences at the level of graphemes and phonemes (Duncan, Seymour, \& Hill, 1997), whereas others have argued that large-size correspondences can also play an important role in beginning reading (Goswami \& Bryant, 1990). More recently it has been recognized that the question of whether small units or large units are used first in reading acquisition may be misplaced. There appears to be evidence for the use of both types of units in children, depending on the nature of the reading task, the type of words being read, the teaching method being used, and the orthography under investigation (Brown \& Deavers, 1999; Goswami \& East, 2000; Goswami, Gombert, \& de Barrera, 1998; Perry \& Ziegler, 2000).

The parallel development of both small-size and large-size units in English is probably an inevitable consequence of the orthographic-phonological relations in English. Small-unit correspondences are initially easy to teach, because individual letters are explicitly represented in the written input. At the same time, however, small units are highly inconsistent in pronunciation. They can be pronounced in multiple ways, and their pronunciation can be spelled in multiple ways (e.g., Berndt, D’Autrechy, \& Reggia, 1994). In contrast, larger units, such as bodies and rhymes, have the advantage of being both less inconsistent (Treiman, Mullennix, Bijeljac-Babic, \& Richmond-Welty, 1995) and more easily accessible in the phonological structure of spoken language (Kirtley, Bryant, MacLean, \& Bradley, 1989). In fact, it seems that prereaders can recognize shared onsets and rhymes in words but are virtually unable to recognize shared phonemes (Goswami \& Bryant, 1990). Thus, larger units are phonologically easier to process but may be orthographically harder to process, as they require the memorization of bigger letter clusters.

This potential conflict between what is easy phonologically versus orthographically has led Brown and Ellis (1994) to argue that beginning readers are faced with the difficult task of establishing a mapping between incompatible levels of representation in the orthographic and phonological domains. The orthographically easy units are phonologically harder (and more inconsistent), whereas the phonologically easy units are orthographically harder (although less inconsistent). Logically, therefore, children learning to read must acquire smallsize phoneme-level representations that can be mapped onto individual graphemes, or develop bigger size orthographic units that can be mapped onto phonological rhymes, or adopt both strategies in parallel. The parallel development of both strategies is the essence of the flexible-unit-size hypothesis (Brown \& Deavers, 1999; Perry \& Ziegler, 2000).

The need to develop both small-unit and large-unit strategies in parallel may be specific to inconsistent orthographies like English, where small grain sizes are highly inconsistent. In orthographically consistent languages like Italian, Spanish, Greek, or German, letters or letter groups map relatively consistently onto sounds, even at small-grain sizes. Indeed, children who are learning to read more orthographically consistent languages appear to develop orthographic representations that code phonology at the smallest grain size (grapheme-phoneme relations) from the beginning of reading (e.g., Frith, Wimmer, \& Landerl, 1998; Goswami et al., 1998; Goswami, Porpodas, \& Wheelwright, 1997; Goswami, Ziegler, Dalton, \& Schneider, 2001; Landerl, Wimmer, \& Frith, 1997; 
Wimmer \& Goswami, 1994). Children who are learning to read less orthographically consistent languages, like English, appear to develop orthographic representations that code phonology at larger grain sizes from the beginning of reading. They supplement grapheme-phoneme encoding with representations for letter patterns for rhymes and representations for whole words (e.g., Goswami, 1999; Wimmer \& Goswami, 1994).

These patterns can be understood in terms of the psycholinguistic grain size hypothesis (Goswami et al., 2001; Ziegler, Perry, Jacobs, \& Braun, 2001). Elsewhere, we have argued that the grain size of the psycholinguistic units that develop for reading differ with orthographic consistency. In orthographically consistent orthographies, like German, readers rely on psycholinguistic units at a small grain size (grapheme-phoneme correspondences). In orthographically inconsistent orthographies, like English readers have no choice but to rely on a variety of psycholinguistic grain sizes, including whole word phonology and orthographic units corresponding to rhymes, in addition to grapheme-phoneme correspondences. This variation for English is not due to the teaching method. A recent study (Landerl, 2000) demonstrated that the German advantage in decoding nonwords that is typically found in comparisons of English and German children was maintained, even when German children were compared to English children receiving intensive phonics tuition. Landerl (2000) compared English children at a pure phonics school with English children receiving the more standard mixed method of reading instruction (a blend of whole word and phonics instruction) and with German children receiving standard (phonics) instruction. The children were given the nonword reading task devised by Wimmer and Goswami (1994). Both English and German children were given nonwords to read based on the number words (e.g., seven-feven, six-tix). Landerl found that the first grade English phonics children made almost as many errors on the nonword reading task (43\%) as the first grade English standard children $(50 \%$, a nonsignificant difference) compared to $12 \%$ errors for a matched German sample. In second grade, a similar pattern was found (English standard $=29 \%$ errors, English phonics $=23 \%$ errors). It was only by third grade that the English phonics children ( $7 \%$ errors) were comparable to the German children $(14 \%$ errors).

In the present study, we tested the psycholinguistic grain size hypothesis in a cross-language comparison. The basic idea was simple. If English children are forced to apply a mixture of small-unit and large-unit strategies in decoding, then reading accuracy for nonwords should benefit when all the nonwords in a block can be successfully decoded by using only one strategy at a time. If a block of nonwords contains familiar large-unit patterns only (large-unit nonwords), then the exclusive application of the large-unit strategy should be very successful. If, in another block, all nonwords contain only unfamiliar large-unit patterns (small-unit nonwords), then decoding should be most successful if an exclusively small-unit strategy is applied. ${ }^{1}$ Accordingly, if both types of nonwords are mixed within a particular block, continual switching between smallunit and large-unit processing should be required, incurring a switching cost. One elegant aspect of such a design is that it enables comparison of exactly the same items. The only difference is that for one group of subjects, the items are 
blocked by nonword type while for the other group they are mixed. Thus, any effect on reading performance must be due to strategy selection rather than to idiosyncratic properties of different groups of nonwords. Such a design has been referred to as the ideal strategy manipulation (Stone \& Van Orden, 1993).

This design allows the interesting prediction that decoding accuracy for both large-unit and small-unit nonwords should be better for English if they are blocked by nonword type than if they are presented mixed together within the same list. In contrast, children who are learning to read an orthographically consistent language like German should be unaffected by a switching cost of this type. These children should prefer small grain size sublexical recoding strategies because of the consistency of letter-sound correspondences, and so there should be no accuracy cost when reading mixed lists.

The present blocking experiments were done in German and English. The German-English comparison is ideal for this purpose because both languages have a similar orthography and phonology but differ quite dramatically in terms of the consistency of correspondences at small grain sizes (Frith et al., 1998; Landerl et al., 1997; Ziegler, Perry, \& Coltheart, 2000). For example, the words ball, park, and hand exist in both languages in identical form; however, the grapheme $a$ receives the same pronunciation in all three words in German but a different pronunciation in each word in English. In theory, these are exactly the kind of inconsistencies at the grapheme level that lead English readers to consider larger units (Treiman et al., 1995). It is important that we used only regular and consistent real words as a basis for devising our nonsense words. Finally, it should be noted that the large-unit and the small-unit nonwords in both orthographies required the same output phonology and articulatory preparation. Hence, any differences that may be found between languages cannot be attributed to articulatory or motor factors. Similarly, any phonological priming between identical large-unit and small-unit phonological forms will be equivalent across languages. Thus, any differences that may be found between languages cannot be attributed to priming. The key manipulation in this experiment involves the comparison of both item types according to mode of presentation (blocked vs. mixed lists). Any priming that may occur within each mode of presentation will thus occur similarly in both languages.

\section{METHOD}

\section{Participants}

For the English children, three groups of 24 subjects at each reading age level (7, 8, and 9 years) took part in the experiment. Half of the children in each reading age group received blocked presentation of the nonsense words and half received unblocked (mixed) presentation. There were 25, 23, and 20 German children tested at 7, 8, and 9 years old, respectively. Thirteen of the 7-year-old children, 9 of the 8-year-old children, and 13 of the 9 -year-old children received blocked presentation. ${ }^{2}$ The groups were matched across language as closely as possible for reading age on standardized tests of reading. Their knowledge of the real words from which the large-unit nonsense words were derived was also 
Table 1. Mean reading age (years; months) and real word knowledge of the experimental groups of English and German children

\begin{tabular}{|c|c|c|c|c|c|}
\hline \multirow[b]{2}{*}{ Language } & \multirow[b]{2}{*}{ Group } & \multirow[b]{2}{*}{ RA } & \multicolumn{3}{|c|}{ Real Word Language (\% Correct) } \\
\hline & & & Monosyll. & Bisyll. & Trisyll. \\
\hline \multirow[t]{6}{*}{ English } & Blocked & $\begin{array}{c}7 ; 7 \\
(1.8)\end{array}$ & $\begin{array}{c}70.3 \\
(15.0)\end{array}$ & $\begin{array}{c}80.2 \\
(20.4)\end{array}$ & $\begin{array}{c}54.2 \\
(26.0)\end{array}$ \\
\hline & Mixed & $7 ; 6$ & $\begin{array}{c}51.1 \\
(23.4)\end{array}$ & $\begin{array}{c}71.0 \\
(25.4)\end{array}$ & $\begin{array}{c}52.8 \\
(33.1)\end{array}$ \\
\hline & Blocked & $\begin{array}{c}8 ; 5 \\
(28)\end{array}$ & $\begin{array}{c}90.6 \\
(8.6)\end{array}$ & $\begin{array}{c}99.5 \\
(18)\end{array}$ & $\begin{array}{c}95.3 \\
(110)\end{array}$ \\
\hline & Mixed & $\begin{array}{c}8 ; 6 \\
(3.0)\end{array}$ & $\begin{array}{l}90.6 \\
(8.6)\end{array}$ & $\begin{array}{l}97.9 \\
(4.1)\end{array}$ & $\begin{array}{c}93.2 \\
(11.1)\end{array}$ \\
\hline & Blocked & $\begin{array}{c}9 ; 4 \\
(3.1)\end{array}$ & $\begin{array}{l}94.8 \\
(9.2)\end{array}$ & $\begin{array}{c}99.0 \\
(2.4)\end{array}$ & $\begin{array}{c}99.0 \\
(3.6)\end{array}$ \\
\hline & Mixed & $\begin{array}{c}9 ; 5 \\
(3.4)\end{array}$ & $\begin{array}{c}87.2 \\
(14.2)\end{array}$ & $\begin{array}{c}100 \\
(0)\end{array}$ & $\begin{array}{c}98.4 \\
(2.8)\end{array}$ \\
\hline \multirow[t]{6}{*}{ German } & Blocked & $\begin{array}{c}7 ; 8 \\
(4.9)\end{array}$ & $\begin{array}{c}95.5 \\
(9.6)\end{array}$ & $\begin{array}{l}97.1 \\
(5.5)\end{array}$ & $\begin{array}{c}90.4 \\
(10.4)\end{array}$ \\
\hline & Mixed & $\begin{array}{c}7 ; 8 \\
(4.0)\end{array}$ & $\begin{array}{l}97.9 \\
(4.9)\end{array}$ & $\begin{array}{c}96.9 \\
(5.7)\end{array}$ & $\begin{array}{l}88.5 \\
(8.4)\end{array}$ \\
\hline & Blocked & $\begin{array}{c}8 ; 4 \\
(3.2)\end{array}$ & $\begin{array}{l}97.9 \\
(4.4)\end{array}$ & $\begin{array}{c}96.5 \\
(8.3)\end{array}$ & $\begin{array}{c}84.7 \\
(15.3)\end{array}$ \\
\hline & Mixed & $\begin{array}{c}8 ; 5 \\
(4.2)\end{array}$ & $\begin{array}{l}98.7 \\
(3.6)\end{array}$ & $\begin{array}{l}99.1 \\
(2.3)\end{array}$ & $\begin{array}{c}85.7 \\
(12.8)\end{array}$ \\
\hline & Blocked & $\begin{array}{c}9 ; 7 \\
(3.6)\end{array}$ & $\begin{array}{c}99.0 \\
(2.3)\end{array}$ & $\begin{array}{c}99.0 \\
(3.5)\end{array}$ & $\begin{array}{c}88.0 \\
(12.6)\end{array}$ \\
\hline & Mixed & $\begin{array}{c}9 ; 10 \\
(1.8)\end{array}$ & $\begin{array}{l}97.3 \\
(7.1)\end{array}$ & $\begin{array}{l}97.3 \\
(4.9)\end{array}$ & $\begin{array}{c}90.2 \\
(10.7)\end{array}$ \\
\hline
\end{tabular}

Note: Standard deviations in months are in parentheses. RA, reading age.

measured. Knowledge of the real words was equivalent across orthography for the older children only (the 8- and 9-year-old children in both orthographies knew 94 and $95 \%$ of the words, respectively). Subject characteristics in the two orthographies are shown in Table 1.

\section{Stimuli}

Two types of nonwords were devised. The large-unit nonwords, like dake, bicket, and dactory (English) and Dot, Lenster, and Laramel (German), had analogous real word neighbors in the mental lexicon (e.g., cake, ticket, and factory; Rot, Fenster, and Karamel). These nonsense words could be read by using rhyme units (lexical analogies) from their real word neighbors or by assembling grapheme-phoneme correspondences. The second type, the small-unit nonwords, had no orthographic rhyme neighbors in the mental lexicon but were phonologically equivalent to the large-unit nonwords (e.g., daik, bikket, and 
dacktori, English; Dodt, Länster, and Larramäll, German). Thus, large-unit nonwords were always orthographic neighbors of their real words; that is, they were only one letter away from their base word (e.g., dake is an orthographic neighbor of fake). However, small-unit nonwords were not orthographic neighbors of the real word; that is, they were more than one letter away from the real base word (e.g., daik is not an orthographic neighbor of fake). ${ }^{3}$ Thus, the orthographic distance between small-unit nonwords and their real words means that small unit nonwords cannot be read by a process of lexical analogy.

The difference between the two groups of nonwords in terms of orthographic distance to the real word can be quantified using the orthographic similarity index (Kwantes \& Marmurek, 1994). This index measures orthographic similarity between a nonword and a real word; it varies between 0 (no orthographic overlap) and 100 (complete orthographic overlap). On this measure, our small unit nonwords were orthographically less similar to real words $(M=51.0)$ than the large unit nonwords $(M=78.8)$. Twenty-four large-unit and 24 small-unit nonwords were created for each orthography. One-third of items were monosyllabic (MS), one-third bisyllabic (BS), and one-third trisyllabic (TS). Again, note that as our key manipulation involves the accurate decoding of both item types according to mode of presentation (blocked or mixed lists), differences in orthographic similarity between large-unit and small-unit nonwords cannot in themselves explain any switching costs that may be found. All items are listed in the Appendix.

\section{Procedure}

Each subject was seen for four experimental sessions. In the first session, the children were given a standardized reading test (English children, the Schonell Graded Word Reading Test, Schonell \& Goodacre, 1971; German children, Würzburger Leise Leseprobe, [Wurzburger Silent Reading Test], Küspert \& Schneider, 1998) and were also asked to read the real words on which the nonsense words were based. In the second, third, and fourth sessions, the nonsense word reading task was administered. Separate sessions were used for each syllable level. Over the experiment, three different orders were used, so that children either received MS, BS, TS, or BS, TS, MS, or TS, MS, BS. In each session, a short word and a nonsense word reading practice at the appropriate syllable level was given, and then the nonsense word reading task was administered.

In the blocked condition, all the large-unit nonsense words at a given syllable level were presented in one list and all the small-unit nonsense words at a given syllable level were presented in another list. The order of receiving the lists was counterbalanced across subjects. In the mixed condition, the large-unit and the small-unit nonsense words at a given syllable level were presented randomly mixed in the same list. ${ }^{4}$ In both conditions, each nonword was repeated twice during the list to increase reliability. A semirandom order was used (so that all eight nonsense words in a given category were seen once before any repeats). The children were asked to read each word as quickly and as accurately as possible. They were instructed to have a guess at a word if they possibly could, and if they were unable to guess they were allowed to say "don't know." 
Prior to each session (syllable group), the children were given two practice lists each comprising six unrelated words and nonsense words. The aim of the practice lists was to familiarize children with nonsense words and with the computerized presentation of the experiment. All tasks were administered on a PowerBook 520c computer using SuperLab software. For each item, a fixation spot appeared for $500 \mathrm{~ms}$ followed by the target word. The responses were taperecorded, allowing any errors to be noted.

\section{RESULTS}

Preliminary analyses showed that the order of presentation of the different syllable lengths had no effect on performance. The percentage of nonsense words read correctly was used as the dependent variable for purposes of analysis. In scoring nonsense word accuracy, any pronunciation that was plausible according to grapheme-phoneme rules was accepted as correct, even if it was not analogous to the real word chosen as a basis for generating the nonsense word. The accuracy data are presented in Table 2.

Inspection of Table 2 suggests that the English children showed strong switching costs in the mixed condition compared to the blocked condition. For the older children, this blocking effect was limited to the monosyllables. For the German children, no systematic switching costs occurred. Hence, an interaction between blocking and language (or possibly blocking, language, and syllable) would be expected. Significant interactions involving the factors of blocking and language are reported below; significant interactions omitting these variables are not reported.

The data were analyzed using analysis of variance, comprising the factorial combination of language (English, German), age (7, 8 or 9 years), blocking (blocked, mixed), nonword type (large unit, small unit), and syllable (MS, BS, TS). The analysis showed significant main effects of language, $F(1,128)=$ $130.5, p<.0001$; age, $F(2,128)=60.0, p<.0001$; nonword type, $F(1,128)=$ $102.7, p<.0001$; and syllable, $F(2,256)=37.8, p<.0001$; and significant interactions between blocking and age, $F(2,128)=3.9, p<.02$; language and syllable, $F(2,256)=40.8, p<.001$; language, age, and syllable, $F(4,256)=$ $3.9, p<.01$; language, blocking, and syllable, $F(2,256)=8.1, p<.001$; language, blocking, and nonword type $F(1,128)=5.0, p<.03$; and language, age, and nonword type, $F(2,128)=6.2, p<.002$. The predicted interaction between language and blocking just failed to reach significance, $F(1,128)=3.3, p<.07$.

For the purpose of the present study, the critical interaction is that between language, blocking, and syllable. Post hoc inspection of this interaction using Newman-Keuls post hoc tests showed that it arose because there was a significant effect of blocking for the monosyllables for the English children only. In the blocked condition the English children read $67 \%$ of the monosyllables correctly; in the mixed condition they read only $49 \%(p<.01)$. Corresponding figures for the German children were 89 and $90 \%$. The three-way interaction between language, blocking, and nonword type was also explored using Newman-Keuls post hoc tests. This interaction suggests that blocking may have different effects on the accuracy of large-unit and small-unit nonword decoding 
Table 2. Mean percentage of nonsense words read correctly as a function of language, condition, nonword type, and word length

\begin{tabular}{|c|c|c|c|c|c|c|c|c|}
\hline \multirow[b]{2}{*}{ Language } & \multirow{2}{*}{$\begin{array}{l}\text { Age } \\
\text { (years) }\end{array}$} & & \multicolumn{3}{|c|}{ Large-Unit Nonwords } & \multicolumn{3}{|c|}{ Small-Unit Nonwords } \\
\hline & & & Blocked & Mixed & Diff. & Blocked & Mixed & Diff. \\
\hline \multirow[t]{9}{*}{ English } & \multirow[t]{3}{*}{7} & Monosyll. & $\begin{array}{c}48.4 \\
(25.9)\end{array}$ & $\begin{array}{c}28.6 \\
(13.2)\end{array}$ & 19.8 & $\begin{array}{l}37.5 \\
(26.4)\end{array}$ & $\begin{array}{c}23.4 \\
(15.6)\end{array}$ & 14.1 \\
\hline & & Bisyll. & $\begin{array}{c}51.0 \\
(30.4)\end{array}$ & $\begin{array}{c}32.8 \\
(22.2)\end{array}$ & 18.2 & $\begin{array}{l}39.1 \\
(26.1)\end{array}$ & $\begin{array}{c}27.6 \\
(19.7)\end{array}$ & 11.5 \\
\hline & & Trisyll. & $\begin{array}{c}26.6 \\
(20.0)\end{array}$ & $\begin{array}{c}8.9 \\
(9.8)\end{array}$ & 16.7 & $\begin{array}{c}7.3 \\
(8.8)\end{array}$ & $\begin{array}{c}3.6 \\
(6.2)\end{array}$ & 3.7 \\
\hline & \multirow[t]{3}{*}{8} & Monosyll. & $\begin{array}{c}79.2 \\
(17.9)\end{array}$ & $\begin{array}{c}66.1 \\
(20.6)\end{array}$ & 13.1 & $\begin{array}{c}61.5 \\
(18.6)\end{array}$ & $\begin{array}{c}58.9 \\
(17.0)\end{array}$ & 2.6 \\
\hline & & Bisyll. & $\begin{array}{c}82.3 \\
(15.3)\end{array}$ & $\begin{array}{c}85.9 \\
(14.6)\end{array}$ & -3.6 & $\begin{array}{c}68.2 \\
(19.7)\end{array}$ & $\begin{array}{c}79.2 \\
(17.5)\end{array}$ & -11.0 \\
\hline & & Trisyll. & $\begin{array}{c}62.5 \\
(16.4)\end{array}$ & $\begin{array}{c}62.0 \\
(23.8)\end{array}$ & 0.5 & $\begin{array}{c}44.3 \\
(18.7)\end{array}$ & $\begin{array}{c}57.8 \\
(22.5)\end{array}$ & -13.5 \\
\hline & \multirow[t]{3}{*}{9} & Monosyll. & $\begin{array}{l}91.7 \\
(16.1)\end{array}$ & $\begin{array}{c}60.0 \\
(27.2)\end{array}$ & 31.7 & $\begin{array}{c}85.9 \\
(13.1)\end{array}$ & $\begin{array}{c}54.2 \\
(28.7)\end{array}$ & 31.7 \\
\hline & & Bisyll. & $\begin{array}{c}95.3 \\
(6.0)\end{array}$ & $\begin{array}{c}89.1 \\
(24.7)\end{array}$ & 6.2 & $\begin{array}{c}85.9 \\
(12.5)\end{array}$ & $\begin{array}{c}83.9 \\
(21.9)\end{array}$ & 2.0 \\
\hline & & Trisyll. & $\begin{array}{c}77.6 \\
(14.0)\end{array}$ & $\begin{array}{c}76.0 \\
(24.7)\end{array}$ & 1.6 & $\begin{array}{c}64.1 \\
(18.1)\end{array}$ & $\begin{array}{c}68.8 \\
(25.0)\end{array}$ & -4.7 \\
\hline Means & & & 68.3 & 56.6 & 11.6 & 54.9 & 50.8 & 4.0 \\
\hline \multirow[t]{9}{*}{ German } & \multirow[t]{3}{*}{7} & Monosyll. & $\begin{array}{c}88.5 \\
(13.0)\end{array}$ & $\begin{array}{l}87.5 \\
(5.3)\end{array}$ & 1.0 & $\begin{array}{c}84.6 \\
(10.4)\end{array}$ & $\begin{array}{c}78.1 \\
(12.1)\end{array}$ & 6.5 \\
\hline & & Bisyll. & $\begin{array}{c}74.0 \\
(23.1)\end{array}$ & $\begin{array}{c}67.7 \\
(17.2)\end{array}$ & 6.3 & $\begin{array}{c}80.8 \\
(16.6)\end{array}$ & $\begin{array}{c}69.8 \\
(18.8)\end{array}$ & 11.0 \\
\hline & & Trisyll. & $\begin{array}{c}76.0 \\
(23.1)\end{array}$ & $\begin{array}{c}78.1 \\
(20.0)\end{array}$ & -2.1 & $\begin{array}{l}81.7 \\
(6.5)\end{array}$ & $\begin{array}{c}78.1 \\
(14.2)\end{array}$ & 3.6 \\
\hline & \multirow[t]{3}{*}{8} & Monosyll. & $\begin{array}{c}90.3 \\
(18.5)\end{array}$ & $\begin{array}{l}98.2 \\
(3.8)\end{array}$ & -7.9 & $\begin{array}{c}79.9 \\
(22.7)\end{array}$ & $\begin{array}{l}93.8 \\
(7.8)\end{array}$ & -13.9 \\
\hline & & Bisyll. & $\begin{array}{c}88.9 \\
(13.9)\end{array}$ & $\begin{array}{l}93.8 \\
(9.8)\end{array}$ & -4.9 & $\begin{array}{l}77.8 \\
(8.9)\end{array}$ & $\begin{array}{c}81.3 \\
(10.4)\end{array}$ & -3.5 \\
\hline & & Trisyll. & $\begin{array}{c}84.7 \\
(23.4)\end{array}$ & $\begin{array}{c}90.2 \\
(10.6)\end{array}$ & -5.5 & $\begin{array}{c}67.4 \\
(30.3)\end{array}$ & $\begin{array}{c}80.1 \\
(12.1)\end{array}$ & -12.7 \\
\hline & \multirow[t]{3}{*}{9} & Monosyll. & $\begin{array}{l}97.1 \\
(5.5)\end{array}$ & $\begin{array}{l}93.8 \\
(7.2)\end{array}$ & 3.3 & $\begin{array}{l}90.4 \\
(9.1)\end{array}$ & $\begin{array}{l}91.1 \\
(7.1)\end{array}$ & -0.7 \\
\hline & & Bisyll. & $\begin{array}{l}93.8 \\
(9.5)\end{array}$ & $\begin{array}{l}92.9 \\
(9.1)\end{array}$ & 0.9 & $\begin{array}{c}74.5 \\
(14.1)\end{array}$ & $\begin{array}{l}68.8 \\
(21.0)\end{array}$ & 5.7 \\
\hline & & Trisyll. & $\begin{array}{c}92.3 \\
(24.1)\end{array}$ & $\begin{array}{c}86.6 \\
(11.7)\end{array}$ & 5.7 & $\begin{array}{c}79.3 \\
(26.1)\end{array}$ & $\begin{array}{c}77.7 \\
(10.1)\end{array}$ & 1.6 \\
\hline Means & & & 87.3 & 87.6 & -0.35 & 79.6 & 79.9 & -0.27 \\
\hline
\end{tabular}

Note: Diff., the size of the blocking effect (i.e., $\%$ blocked $-\%$ mixed). A positive number reflects a blocking advantage. Standard deviations are in parentheses. 
by language. Post hoc inspection revealed that the English children benefited from blocked presentation for both nonword types. However, the blocking effect was larger for the large-unit nonwords (blocked presentation, 68.3\% correct; mixed presentation, $56.6 \%$ correct; $p<.01)$ than for the small-unit nonwords (blocked presentation, $54.9 \%$ correct; mixed presentation, $50.8 \%$ correct; $p<$ $.05)$. The German children's nonword reading accuracy was unaffected by the blocking manipulation for both the large-unit and the small-unit nonwords (large-unit nonwords, blocked presentation, $87.3 \%$ correct, mixed presentation, $87.6 \%$ correct; small-unit nonwords, blocked presentation, $79.6 \%$ correct, mixed presentation, $79.9 \%$ correct). Finally, the three-way interaction between language, age, and nonword type was explored using Newman-Keuls post hoc tests. Post hoc inspection showed that the German 7-year-olds showed no advantage in reading the large-unit nonwords, in contrast to all other groups who showed an approximately $10 \%$ advantage for the large-unit nonwords over the small-unit nonwords (an effect of orthographic familiarity). Again, this supports our hypothesis that German children begin reading by using psycholinguistic units at a small grain size (grapheme-phoneme correspondences). This decoding strategy is very successful and probably inhibits learning about larger consistencies within the orthography until decoding is less effortful and larger spelling consistencies become more salient.

As the German children were better overall at reading the nonsense words, despite being matched to the English children for reading age, it is possible that ceiling effects could be causing the theoretically important interaction found between language, blocking, and syllable. It was thus decided to carry out a further analysis comparing the English 9-year-olds to the German 7-year-olds. These two groups were approximately equivalent in their nonsense word reading levels $($ English $=77.7 \%$ correct, German $=78.7 \%$ correct, see Table 2 ). If the interaction between language, blocking, and syllable remains robust across this very stringent comparison, then the hypothesis that English children benefit more from blocking than German children would be supported. The analysis was a $2 \times 2 \times 2 \times 3$ (Language: English, German; Blocking: Blocked, Mixed; Nonword type: large unit, small unit; and Syllable: MS, BS, TS), taking the number of nonsense words read correctly as the dependent variable. The predicted interaction between language, blocking, and syllable remained significant, $\mathrm{F}(2,90)=8.5, p<.0001$. The English children read $89 \%$ of the monosyllabic nonwords correctly in the blocked condition, compared to $57 \%$ in the mixed condition. The German children read $86.5 \%$ of the monosyllabic nonwords correctly in the blocked condition compared to $83 \%$ in the mixed condition. This supports our general hypothesis that English children are developing sublexical recoding procedures at both the large-unit and small-unit levels. German children are more reliant on sublexical recoding procedures at the smallunit grapheme-phoneme level. Accordingly, the English children show an advantage in decoding large-unit nonwords that is absent in the German children.

\section{DISCUSSION}

The present article investigated the flexible-unit-size hypothesis (Brown \& Deavers, 1999; Perry \& Ziegler, 2000). This hypothesis claims that young En- 
glish readers are forced to use at least two reading strategies: a small-unit strategy to reduce visual/orthographic complexity of large orthographic clusters and a large-unit strategy to reduce inconsistency that is maximal at the graphemephoneme level in English. In contrast, reading in a shallow orthography like German can be very successful using a small-unit grapheme-phoneme decoding strategy only, because of relative orthographic consistency at the small grain size level.

This hypothesis was tested using an ideal strategy manipulation together with a cross-language comparison. We employed nonwords in both languages that could either only be read using a small-unit strategy or that encouraged a largeunit strategy of lexical analogy. We predicted that, in a mixed list, English readers would have to switch back and forth between small-unit and large-unit processing, resulting in switching costs. In a blocked list, English readers should be able to focus on one grain size, resulting in a decoding advantage. German readers should not show blocking effects, because they should always operate at a small-unit grain size.

The data revealed strong switching costs in mixed lists for the English readers but not for the German readers. For the English children, this effect was only significant for the monosyllabic items. Monosyllabic items benefit maximally from body-level processing, and this will be reflected in the reading system as children gain more reading experience. Consistent with this explanation, Ziegler et al. (2001) recently showed that adult English readers exhibit strong facilitatory body neighborhood effects whereas German readers show no evidence of body neighborhood effects, even when identical monosyllables are compared across the two languages (e.g., sand/Sand). Clearly, skilled German readers continue to rely on small-size units. Meanwhile, the large-unit effects characteristic of English children remain characteristic of English adults.

The strongest aspect of the present design is that our conclusions are not based on absolute processing differences between different groups of items (e.g., large-unit nonwords versus small-unit nonwords). Instead, identical items are presented in both blocked and mixed lists. Blocking seems to help the English reader to focus on one grain size of processing, which particularly increases decoding accuracy for large unit items. German readers do not show these blocking effects because hypothetically they already rely on general and efficient processing at a small-unit level.

Our results suggest that the choice of reading units in English is flexible and adaptive, as postulated by the flexible unit size hypothesis. However, this flexibility comes at a price, as the orthographic-phonological relations in English take longer to acquire. English children typically show high accuracy in nonword reading at a later reading level than German or Spanish children (Goswami et al., 1998, 2001; Landerl, 2000). We suggest that English flexibility in sublexical processing is an inevitable consequence of the nature of the orthography being acquired. 


\section{APPENDIX}

\begin{tabular}{|c|c|c|}
\hline Real Words: English & Large Unit & Small Unit \\
\hline \multicolumn{3}{|l|}{ Monosyllables } \\
\hline Fake & Dake & Daik \\
\hline Turn & Murn & Mirn \\
\hline Tape & Fape & Faip \\
\hline Dull & Rull & Rul \\
\hline Robe & Tobe & Toab \\
\hline Muff & Guff & Guf \\
\hline Girl & Rirl & Rerl \\
\hline Page & Tage & Taij \\
\hline \multicolumn{3}{|l|}{ Bisyllables } \\
\hline Ticket & Bicket & Bikket \\
\hline Little & Kittle & Kittel \\
\hline Butter & Tutter & Tutta \\
\hline Taxi & Paxi & Packsi \\
\hline Pillow & Tillow & Tilloe \\
\hline Coffee & Loffee & Loffi \\
\hline Comic & Womic & Wommick \\
\hline Window & Tindow & Tindo \\
\hline \multicolumn{3}{|l|}{ Trisyllables } \\
\hline Factory & Dactory & Dacktori \\
\hline Banana & Danana & Dannarnar \\
\hline Daffodil & Baffodil & Baffoddyl \\
\hline Dinosaur & Sinosaur & Synosor \\
\hline Hospital & Pospital & Posspital \\
\hline Potato & Fotato & Fottatoe \\
\hline Pyjamas & Tyjamas & Tijarmas \\
\hline Tomato & Pomato & Pomartoe \\
\hline \multicolumn{3}{|l|}{ Real Words: German } \\
\hline \multicolumn{3}{|l|}{ Monosyllables } \\
\hline Hund & Tund & Tunt \\
\hline Berg & Gerg & Gärg \\
\hline Rot & Dot & Dodt \\
\hline Haus & Faus & Fauss \\
\hline Kind & Zind & Zindt \\
\hline Mond & Rond & Roond \\
\hline Fünf & Sünf & Sünv \\
\hline Dorf & Lorf & Lorv \\
\hline \multicolumn{3}{|l|}{ Bisyllables } \\
\hline Lesen & Nesen & Neesen \\
\hline Blume & Plume & Pluume \\
\hline Braten & Jaten & Jaaten \\
\hline Vater & Gater & Gahter \\
\hline Fenster & Lenster & Länster \\
\hline Nase & Tase & Tahse \\
\hline Bruder & Kluder & Kluhder \\
\hline BMesser & Flesser & Flässer \\
\hline
\end{tabular}


Goswami et al.: Flexible reading

APPENDIX (cont.)

\begin{tabular}{lll} 
Real Words: German & Large Unit & Small Unit \\
\hline \hline Trisyllables & & \\
Tomate & Momate & Mohmahte \\
Spiegelei & Friegelei & Frigelai \\
September & Reptember & Rebtämber \\
Verlieren & Nerlieren & Närlihren \\
Karamel & Laramel & Larramäll \\
Besenstiel & Vesenstiel & Veesenstihl \\
Spaghetti & Blaghetti & Blaggätti \\
Banane & Ganane & Gannaane \\
\hline \hline
\end{tabular}

\section{ACKNOWLEDGMENTS}

We would like to thank the teachers and children of St. Luke's Primary School, St. Lawrence's Primary School, and St. Andrew's Primary School, Cambridge, UK; four Grundschulen in Würzburg; and the Dietrich-Bonhoeffer-Schule, Dietzenbach, Germany, for taking part in these studies. We also thank Angelika Neumann for her help with testing and data analysis. Support for this research was partly provided by a Medical Research Council Project Grant (G9326935N) and a von Humboldt Research Fellowship from the Alexander von Humboldt Foundation, both to Usha Goswami. Preparation of this article was supported by an Alliance travel grant to Usha Goswami and Johannes Ziegler (PN 00.2300).

\section{NOTES}

1. Note that the word strategy is not intended to refer to the conscious application of a particular reading strategy by the child. Rather, it refers to the inevitable ways in which internal representations will develop given the particular training environments that the learning mechanism is exposed to (viz., orthographies that are either consistent or inconsistent at smaller grain sizes).

2. The numbers of 8- and 9-year-old children in the blocked and mixed conditions were not equally matched due to an experimenter error.

3. We realized later that the German small unit word tunt did have a large-unit analogy (bunt). However, this is not particularly problematic for our design because the critical effect was not the comparison between large-unit versus small-unit words but whether the same items were processed differently, depending on whether they occurred in blocked or mixed lists.

4. For the mixed condition, six unrelated nonsense words at each syllable level were included in the lists. This was assumed to reduce the likelihood of the child noticing that the same phonological patterns were repeating. The extra nonsense words were the O-P-nonsense words (requiring small grain size strategies) from Goswami et al. (1997).

\section{REFERENCES}

Berndt, R. S., D'Autrechy, C. L., \& Reggia, J. A. (1994). Functional pronunciation units in English words. Journal of Experimental Psychology: Learning, Memory, \& Cognition, 20, 977-993. 
Brown, G. D. A., \& Deavers, R. P. (1999). Units of analysis in nonword reading: Evidence from children and adults. Journal of Experimental Child Psychology, 73, 208-242.

Brown, G. D. A., \& Ellis, N. C. (1994). Issues in spelling research. In G. D. A. Brown \& N. C. Ellis (Eds.), Handbook of spelling: Theory, process and intervention (pp. 3-25). Chichester, UK: Wiley.

Duncan, L. G., Seymour, P. H. K., \& Hill, S. (1997). How important are rhyme and analogy in beginning reading? Cognition, 63, 171-208.

Frith, U., Wimmer, H., \& Landerl, K. (1998). Differences in phonological recoding in German- and English-speaking children. Scientific Studies of Reading, 2, 31-54.

Goswami, U. (1999). Causal connections in beginning reading: The importance of rhyme. Journal of Research in Reading, 22, 217-240.

Goswami, U., \& Bryant, P. E. (1990). Phonological skills and learning to read. Hillsdale, NJ: Erlbaum.

Goswami, U., \& East, M. (2000). Rhyme and analogy in beginning reading: Conceptual and methodological issues. Applied Psycholinguistics, 21, 63-93.

Goswami, U., Gombert, J. E., \& de Barrera, L. (1998). Children's orthographic representations and linguistic transparency: Nonsense word reading in English, French, and Spanish. Applied Psycholinguistics, 19, 19-52.

Goswami, U., Porpodas, C., \& Wheelwright, S. (1997). Children's orthographic representations in English and Greek. European Journal of Psychology of Education, 12, 273-292.

Goswami, U., Ziegler, J., Dalton, L., \& Schneider, W. (2001). Pseudohomophone effects and phonological recoding procedures in reading development in English and German. Journal of Memory \& Language, 45, 648-664.

Kirtley, C., Bryant, P., MacLean, M., \& Bradley, L. (1989). Rhyme, rime, and the onset of reading. Journal of Experimental Child Psychology, 48, 224-245.

Küspert, P., \& Schneider, W. (1998). Würzburger Leise Leseprobe [Würzburger Silent Reading Test]. Hogrefe, Germany: Göttingen.

Kwantes, P. J., \& Marmurek, H. H. C. (1994). Orthographic effects in reading pseudohomophones. Paper presented at the 35th annual meeting of the Psychonomic Society, St. Louis, MO.

Landerl, K. (2000). Influences of orthographic consistency and reading instruction on the development of nonword reading skills. European Journal of Psychology of Education, 15, 239-257.

Landerl, K., Wimmer, H., \& Frith, U. (1997). The impact of orthographic consistency on dyslexia: A German-English comparison. Cognition, 63, 315-334.

Perry, C., \& Ziegler, J. C. (2000). Linguistic difficulties in childhood constrain adult reading. Memory and Cognition, 28, 739-745.

Schonell, F., \& Goodacre, E. (1971). The psychology and teaching of reading. London/Edinburgh: Oliver \& Boyd.

Stone, G. O., \& Van Orden, G. C. (1993). Strategic control of processing in word recognition. Journal of Experimental Psychology: Human Perception \& Performance, 20, 1248-1268.

Treiman, R., Mullennix, J., Bijeljac-Babic, R., \& Richmond-Welty, E. D. (1995). The special role of rimes in the description, use, and acquisition of English orthography. Journal of Experimental Psychology: General, 124, 107-136.

Wimmer, H., \& Goswami, U. (1994). The influence of orthographic consistency on reading development: Word recognition in English and German children. Cognition, 51, 91-103.

Ziegler, J. C., Perry, C., \& Coltheart, M. (2000). The DRC model of visual word recognition and reading aloud: An extension to German. European Journal of Cognitive Psychology, 12, 413-430.

Ziegler, J. C., Perry, C., Jacobs, A. M., \& Braun, M. (2001). Identical words are read differently in different languages. Psychological Science, 12, 379-384. 